Slander," in The Journal, September 12, permit me to suggest that Leffingwell has made to serve his purpose a state. ment which, in itself true and authenticated, does in no wise refer to vivisectors and their work. Krafft-Ebing, in his "Psychopathia Sexualis," page 84 et seq., says, in discussing sadism:

In numerous cases, sadistically perverse men, that are afraid of criminal acts with human beings, or that care only for the sight of the suffering of a sensitive being. make use of the sight of dying animals, or torture animals, to stimulate or excite their the vita sexualis is so constituted. ab origine, that the sight of blood, death, etc., excites lustful feeling.

I think it very probable that Leffingwell has used the above quotation for his purpose. The fact that it does not at all serve, except through the lie, and that the whole argument is "an den Haaren herbei gezogen," has troubled him but little.

H. J. Achard.

\section{The Physiologic Generation Cycle of Woman.}

Mairayoy City, Pa., Sept. 9, 1903.

To the Editor:-In TIE Journal, September 5, page 627, synopsis of Dr. Jennie G. Drennan's paper on the "Physiologic Generation Cycle of Woman," the following statement is made:

In mammals and primitive roman ovulation occurs at distinct periods of the year and at no other time. Mating with the primitive woman was much like that of the brute creation now : as soon as she was sexually mature she mar'tied and entered on the physiologic cycle of a mammal, etc.

It has seemed to me in the course of my studies that ovu. lation depended more on the abundance of food at the command of woman than any other cause, regardless of the stage at which she lived in the history of civilization. I wish Dr. Drennan would state the grounds on which she bases her statement, for it is a very interesting scientific fact if primitive woman differs so radically from her sister in civilization.

Geo. W. Reese.

\section{Queries and Minor Notes.}

Anoxymous Commonicatioxs will not be noticed. Querles for this column must be accompanied by the writer's name and address, but the request of the writer not to publish his name will be faithfully observed.

\section{LIMITS OF CONSANGUINEOUS MARRIAGES.}

Sept. 12, 1903.

To the Editor:-Will you kindly inform me through the "Queries and Minor Notes" whether the offspring from the marriage of second cousins are generally considered beyond the defects and deformities resulting from consanguinity? If not, what per cent. are considered so afficted? $\quad$ E. G. B.

Axs.- A second consin has only half the common heredity of a first cousin. According to Galton's calculation, their respective amounts can be represented by $1 / \mathrm{S}$ and $1 / 16$; therefore, the chances of morbid heredity would not be more than one-half, probably less. There has been no legislation against the marriage of second cousins anywhere, so far as we know, and we believe such marriages are generally considered comparatively safe as regards offspring. Still, in special cases, there might be a concentration of the common heredity even beyond this degree of relationship. As to in what percentage of cases this would occur, we know of no way of determining.

\section{CONDUCT AFTER SALE OF PRACTICE AND SUPPOSED PIRMANENT REMOVAL.}

Crty of Mexico, Aug. 21, 1903.

To the Editor:-Please publish your opinion of the ethics of the following case: Three years ago $A$ hired $B$ to go to a foreign country, where $A$ was established, and assist him. $B$ was to have a salary the first year and a third interest in the business the second year. At the beginning of the second year $B$ prefers an increased salary to the third interest, and is accommodated, but still claims the right to the third interest at the end of the second year. This is agreed to. During the second year $B$ becomes dissatisfied on account of ill health, and desires to return to the United States. A induces $C$ to purchase the interest of $B$ in the business, which he does, paying therefor $\$ 1,000$, which $B$ accepts and Immediately returns to the United States, having previously introduced $\mathrm{C}$ to as many of his patrons as the time permitted. No contract or papers were signed. $B$ returns in a few months and resumes independent practice, claiming that he has a right to do so. Did he act honorabiy?
Axs.-To the ex parte statement made by our inquirer, there can be but one answer, and that is that B did not act honorably, to say the least. Furthermore, there certainly is redress for $\mathrm{C}$ if he should go to law. C paid $\$ 1,000$ for E's practice and good will, which meant that $B$ must give up his practice and good will. By bis returning and entering into practice again, he took back the two things that he sold. He should, therefore, give back the $\$ 1,000$.

\section{RIGORS IN TYPHOID WITH HIGH TEMPERATURE.}

Americus, GA., Aug. 31, 1903.

To the Editor:-In typhoid fever, characterized by high tempera ture, rigors occur when the temperature is the highest. These rigor's are not due to malaria; the patient will have them when thoroughly cinchonized. Can you give me the cause of this?

\section{J. C. FrELD, M.D.}

Axs.-In typhoid, chills occasionally occur where no clear explanation of their cause can be offered. Perhaps the most frequent time of the occurrence of severe chills is during convales cence, when there may be repeated rigors. Why this is so is not plain. Of course, chills at the onset are not so very unusual. And complications, such as pneumonia, parotitis, malaria or secondary infection with pyogenic organlsms, may be ushered in by a chill, and where antipvrin, acetanilid or phenacetin have been used with a free hand chills are not infrequent. Perhaps the chills that occur during the course of the disease are at times due to the sudden invasion of the blood by unusually large numbers of typhoid bacilli, or the unusually rapid development of the germs within the blood. Complications that are often unrecognizable, as in the mesenteric glands or gall bladder. may explain them at times. Constipation, with its attendant absorptive toxemia, is held by some to be the cause of some of the chills of typhoid fever. Until more is known of the real physics and chemistry of chill production in general. some of the chills of typhoid must go unexplained. Certainly. in the cases mentioned by our correspondent, malaria is ruled out as a cause. for not only does malaria, when it complicates typhoid. usually manifest itself during convalescence, but it will not resist quinin if freely given.

A full discrission of the subject of chills in typhoid fever will be found in Osler's "Studies on Typhoid Fever," Series II, in the Johns Hopkins Hospital Reports, Vol. IV, and in Vol. VIII, p. 443, et seq. See. also. the recent article by Dr. Delafield in the Hedical Record, September 12, on "Post-typhoid Sepsis," abstracted in oul next issue.

\section{Miscellany.}

Information Wanted of a Fraudulent Agent.-Dr. W. H. Snyder, who recently reported a fraudulent solicitor for Colliers' Weekly, reports that Mr. L. H. Bortner, the local manager for Collier, called and fulfilled the contract, although they did not receive the money. Mr. Bortner, whose address is 50 Law Building, Toledo, Ohio, wishes information of any other physician who subscribed with this agent or information as to the agent's whereabouts.

\section{Marriages.}

James Ingersoll Wernham, M.D., to Miss Winifred Patrick, both of Marengo, Ill., September 9.

Oscar L. Fullerton, M.D., Redding, Iowa, to Miss Eva L. Johnson of Neva, Mo., September 2.

Clifton Meredith Miller, M.D., Richmond, Va., to Miss Mary Ashley Bell of Fluvanna County, Va., at Wilmington, Va., September 3.

James V. Convish, M.D., Quiney, Ill., to Miss Lettie S. McConnell of Ellington Township, Adams County, Ill.; September 6 .

\section{Deaths.}

Charles F. W. Myers, M.D. College of Physicians and Surgeons, New York, 1874, a member of the American Medical Association; lieutenant colonel and medical director, N. G., N. J., and a member of the Association of Military Surgeons of the United States, who had been in ill health for several years, died August 31, from apoplexy, at his home in Paterson, N. J., aged 54 .

Nelson V. Prewitt, M.D. University of Virginia, Charlottes ville, 1893, of Winchester, Ky., a member of the Clark County Medical Society, Kentucky Valley Medical Association, Kentucky State Medical Association and the American Medical 